\title{
Arabidopsis thaliana Expresses Multiple Lines of Defense to Counterattack Erwinia chrysanthemi
}

\author{
Mathilde Fagard, ${ }^{1}$ Alia Dellagi, ${ }^{1}$ Camille Roux, ${ }^{1}$ Claude Périno, ${ }^{1}$ Martine Rigault, ${ }^{1}$ Virginie Boucher, ${ }^{1}$ \\ Vladimir E. Shevchik, ${ }^{2}$ and Dominique Expert ${ }^{1}$ \\ ${ }^{1}$ Laboratoire Interactions Plantes-Pathogènes, UMR 217 INRA/INA P-G/Université Paris 6 and CNRS, 16 rue Claude \\ Bernard, Paris 75005, France; ${ }^{2}$ Unité de Microbiologie et Génétique, UMR 5122 CNRS/INSA/UCB, Université Lyon 1, \\ F-69622 Villeurbanne cedex, France
}

Submitted 11 October 2006. Accepted 7 February 2007.

\begin{abstract}
Many taxonomically diverse plant species are attacked by Erwinia chrysanthemi, a member of the causal agents of soft-rotting diseases. Symptom development is due to the collective action of pectin-degrading enzymes secreted by the bacterium through a type II secretion system (T2SS). Using Arabidopsis thaliana as a susceptible host, we show that plants respond to $E$. chrysanthemi 3937 by expressing cell-wall reactions, production of an oxidative burst, and activation of salicylic acid (SA) and jasmonic acid (JA) or ethylene (ET) signaling pathways. We found that the oxidative burst is mainly generated via the expression of the AtrbohD gene, constitutes a barrier of resistance to bacterial attack, and acts independently of the SA-mediated response. To determine the importance of T2SS-secreted proteins in elicitation of these defenses, we used a T2SS deficient mutant and purified enzymatic preparations of representative members of strain 3937 pectate lyase activity. The T2SS-secreted proteins were responsible only partially for the activation of SA and JA or ET signaling pathways observed after infection with the wild-type bacterium and were not involved in the expression of other identified defense reactions. Our study shows the differential role played by pectate lyases isoenzymes in this process and highlights the complexity of the host immune network, which is finely controlled by the bacterium.
\end{abstract}

In response to pathogen attack, plants activate multiple defense reactions both at the site of infection and systemically. These reactions include massive transcriptional reprogramming, production of reactive oxygen species (ROS), reinforcements of the cell wall, such as accumulation of hydroxy-proline-rich glycoproteins (HRGP) and callose deposition, synthesis of antimicrobial metabolites, and pathogenesis-related (PR) proteins involved in resistance (Bowles 1990; Glazebrook et al. 2003; Lamb and Dixon 1997). The molecular mechanisms underlying activation of plant defense responses proved to be extremely complex and depend on whether the host is resistant or susceptible. Host resistance can culminate in the formation of a hypersensitive reaction (HR), considered as a form of programmed cell death confining the pathogen to a restricted area (Lam et al. 2001). Susceptible hosts may express defense responses that are not fast enough to stop pathogen growth. Plant immune reactions involve three major signaling molecules, salicylic acid

M. Fagard and A. Dellagi contributed equally to this work.

Corresponding author: D. Expert; E-mail: expert@inapg.fr
(SA), jasmonic acid (JA), and ethylene (ET). A number of studies aimed at deciphering the mechanisms of plant immunity support the idea that the outcome of infection relies on the interconnected expression of the signaling cascades mediated by these molecules (Katagiri 2004). These cascades can be mutually antagonistic, and microbes seem to divert them to take over (Reymond and Farmer 1998; Truman et al. 2006).

$\mathrm{SA}$ is considered a major actor in the establishment of different defensive barriers against pathogens. The biosynthesis of SA in A. thaliana is mainly achieved through the isochorismate pathway, which involves isochorismate synthase encoded by the ICS1 gene and is impaired in sid2 mutants (Nawrath and Métraux 1999; Wildermuth et al. 2001). SA is a main regulator of systemic acquired resistance and PR protein induction (Durrant and Dong 2004; Sticher et al. 1997), but the SA perception mechanism is not well understood (Métraux 2002). It seems likely that SA interferes with the plant intracellular redox status, as production of SA leads to modifications in the oligomeric form of the cytosolic NPR1 protein, which results in transfer of this protein into the nucleus and $P R I$ transcriptional activation (Mou et al. 2003). SA was shown to act in association with reactive oxygen species (ROS) in signaling cascades that lead to different forms of resistance, but the exact nature of the mechanisms involved has not been determined (Torres et al. 2006). The main enzymatic sources for ROS production in $A$. thaliana upon interaction with pathogens were identified as respiratory burst oxidase homologs, i.e., the NADPH-oxidases referred to as AtrbohD and AtrbohF (Torres et al. 2006). These enzymes are members of a ten-homolog family in A. thaliana. They reduce dioxygen into superoxide anion that is then converted into hydrogen peroxide.

Ethylene sensing involves membrane-anchored receptors and leads to the activation of transcriptional factors via MAPK signaling cascades (Broekaert et al. 2006). Ethylene-insensitive mutants are highly susceptible to necrotrophic fungal pathogens such as Botrytis cinerea (Thomma et al. 1999). However, pharmacological approaches have shown that ethylene can have opposite effects with regard to development of symptoms, depending on the time of ethylene or ethylene precursor exposure (Van Loon et al. 2006). JA is a member of a large family of fatty-acid-derived signaling molecules (La Camera et al. 2004). Perception of JA involves ubiquitin-dependent proteolysis of proteins with unknown functions and the modification of JA by the JAR1 protein (Staswick et al. 2002; Xu et al. 2002). ET- and JA-mediated signaling pathways are often considered as synergistic and strongly interdependent, resulting in the expression of defense genes encoding the defensin PDF1.2 and the basic chitinase CHI-B (Lorenzo and Solano 2005). Collectively, the nu- 
merous studies investigating the role of defense pathways in the outcome of disease indicate that ET and JA pathways are efficient against necrotrophs, whereas SA is more efficient against biotrophs (Glazebrook 2005).

Pathogenic bacteria have developed accurate mechanisms enabling them to overcome host defenses and to gain access to essential nutriments. For a plant-pathogenic bacterium, a major challenge is to cope with the presence of rigid walls based on a complex matrix made of pectin and cellulose or hemicellulose surrounding the plant cell (Willats et al. 2001). Erwinia chrysanthemi (syn. Dickeya dadantii) is a member of the family Enterobacteriaceae that overcomes this obstacle by degrading pectin, causing soft rot in a wide range of plants. This species produces a wide array of enzymes that break down linear and ramified regions of pectin. These include pectin methyl esterases, pectin acetyl esterases, exo- and endopectate lyases, and exopolygalacturonases (Robert-Baudouy et al. 2000). In $E$. chrysanthemi 3937, a rhamnogalacturonate lyase was also described (Laatu and Condemine 2003). The main causative factors of maceration are the endopectate lyases (Robert-Baudouy et al. 2000). Endopectate lyases cleave polygalacturonate into oligomers that can then be used by the bacteria as a carbon source. Interestingly, synthesis of these enzymes is finely controlled by a set of transcriptional regulators that respond to metabolic stimuli and environmental conditions, including pectin breakdown products, iron availability, temperature, nitrogen starvation, osmolarity, oxygen limitation, and growth phase (Robert-Baudouy et al. 2000). Pectinases are secreted in the plant apoplasm by a type II secretion system (T2SS) referred to as an Out system (Bouley et al. 2001; Douet et al. 2004). This system is a transenvelope structure enabling secreted proteins to cross the inner and outer membranes in a stepwise process (He et al. 1991). In strain 3937, the fourteen E. chrysanthemi out genes encoding this machinery are organized in five operons (Condemine and Robert-Baudouy 1995). out-negative mutants fail to produce symptoms on host plants. Besides cell-wall-degrading enzymes, other factors contribute to $E$. chrysanthemi pathogenicity. Among them, high-affinity ferric iron acquisition systems mediated by two siderophores (Expert 1999; Franza et al. 2005), [Fe-S] cluster assembly machinery (Nachin et al. 2001, 2003), and enzymes detoxifying ROS are important for bacterial survival and dissemination in planta (Favey et al. 1995; Hassouni et al. 1999; Santos et al. 2001). The importance of these factors in the interaction has been assessed by the analysis of bacterial mutants inoculated on African violets (Saintpaulia ionantha) and chicory leaves.

In light of these data, we examined whether E. chrysanthemi 3937 induces plant defense reactions. In a previous work, Dellagi and associates (2005) showed that A. thaliana is able to control its iron metabolism in response to E. chrysanthemi attack. To deepen our knowledge of this interaction, we conducted a detailed analysis of the infectious process of strain 3937 in A. thaliana. We decrypted a number of defense responses that can be overcome by the bacteria during their course in the host. Interestingly, we found that the production of an oxidative burst is a main defense reaction that contributes to host resistance. Our results show that cell-wall-degrading enzymes are not the only effectors activating $A$. thaliana immune responses and highlight the complexity of the interplay between the two partners.

\section{RESULTS}

\section{E. chrysanthemi degrades the cell wall}

of A. thaliana and triggers cell-wall defenses.

E. chrysanthemi 3937 causes a maceration symptom on $A$. thaliana plants reminiscent of that described on African violets, regardless of the mode of inoculation, leaf infiltration, or spotting. At $24 \mathrm{~h}$ after inoculation of a single $A$. thaliana leaf, we observed a maceration, which progressively spread to the base of the petiole (Dellagi et al. 2005). In 50 to $75 \%$ of infected plants, we could observe a partial or whole collapse of the aerial part within 5 to 6 days, indicating that the bacteria can disseminate throughout the plant.

To gain insight into this process, we investigated the migration of bacteria within plant tissues. Examination of thin sections of infected leaves stained with toluidine blue showed that cell walls in parenchyma of symptomatic regions were degraded, resulting in highly disorganized tissues containing large numbers of bacterial cells (Fig. 1A). At the border of macerated regions, we detected the presence of many bacteria colonizing the intercellular spaces and walls (Fig. 1A and C). In these asymptomatic regions, there was no apparent tissue disorganization. This mode of dissemination was further observed by electron microscopy (EM) (Fig. 1D). We never observed the presence of bacteria in xylem vessels. We checked whether wall degradation by E. chrysanthemi in A. thaliana was comparable to that observed in infected Saintpaulia ionantha plants (Murdoch et al. 1999). We found a progressive disappearance of methyl esterified homogalacturonan and rhamnogalacturonan structures in the cell walls of parenchyma cells located at the border of the macerated region; cellulose was only partially degraded (data not shown). In asymptomatic areas, major cell-wall components were not yet degraded.

We wondered whether the degradation of the cell wall by $E$. chrysanthemi led to a response of the plant at the site of the wall itself. We analyzed the accumulation of two components that have been associated with wall-based defense, HRGP, and callose (Bowles 1990). In cells located at the border of the degraded region, we observed a labeling with the LM1 antibody indicating the presence of HRGP (Fig. 1F and G), which was not visible in healthy leaves (Fig. 1E). LM1 staining was observed in asymptomatic regions, indicating that HRGP accumulation preceded the degradation of the wall by the bacteria. We could also detect callose deposits $8 \mathrm{~h}$ postinoculation (hpi) in the extracellular compartment of parenchyma and along vascular tissues (Fig. 1I). We never observed such deposits in mock-treated leaves (Fig. 1H). Both callose and HRGP were found to accumulate before symptoms were observed, indicating that they are probably a response of the plant following perception of the presence of bacteria and not a result of cellwall degradation.

These data led us to consider the existence of two distinct phases in the infection process. One is asymptomatic, the bacteria progress intercellularly with no substantial multiplication; the other one is symptomatic, during which bacteria thrive (Fig. 1A; Franza et al. 2005). The presence of HRGP and callose as a change in cell-wall structure in response to infection suggested that the host perceived the bacterium as an intruder. We thus investigated whether the plant developed more immune responses.

\section{Oxidative burst, a defense}

\section{of $A$. thaliana against $E$. chrysanthemi.}

Previous studies (Santos et al. 2001) suggested that, in vivo, the bacteria have to cope with production of ROS caused by bacterial attack. Thus, we investigated whether superoxide anions and hydrogen peroxide were produced following infection.

Leaves infected with wild-type strain were checked for the production of superoxide with nitroblue tetrazolium (NBT) as an indicator. A blue formazan precipitate surrounding the macerated region was detected (Fig. 2A). Microscopically, the coloration appeared confined to undamaged plant cells surrounded by bacteria. Precipitates were localized in chloroplasts and in 
wall spaces (data not shown). We analyzed the production of hydrogen peroxide at different timepoints after inoculation, using 3, 3'-diaminobenzidine (DAB) as an indicator. The coloration became visible after 9 hpi and increased over time (Fig. 2B, 12-hpi timepoint), until the tissues were degraded.
After $24 \mathrm{~h}$, brown precipitates had spread throughout the leaf (data not shown).

We then investigated the possibility that ROS were generated by one or more plant NADPH oxidases. To this end, we used $A$. thaliana T-DNA insertion lines harboring either simple

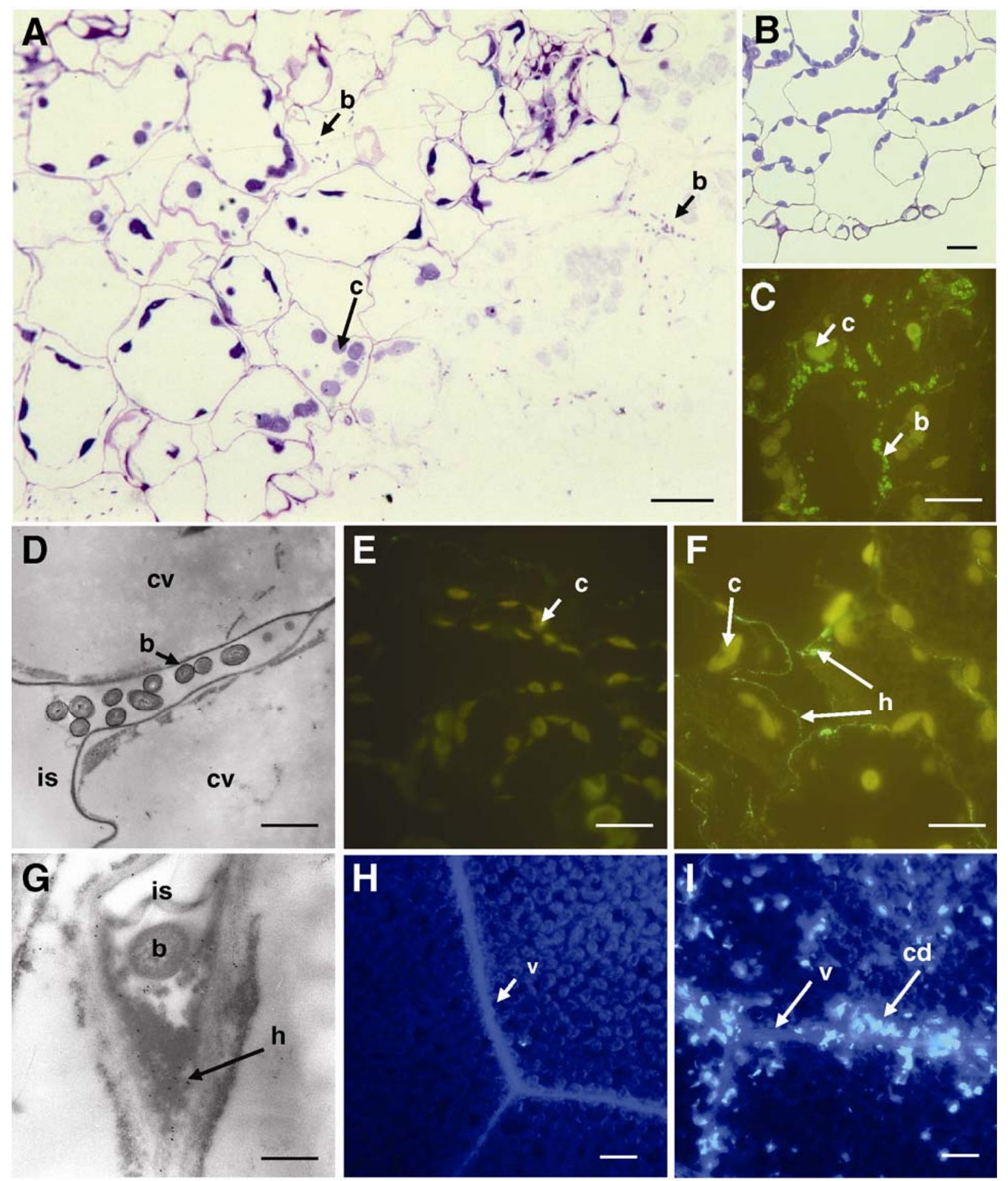

Fig. 1. Microscopic analysis of the Erwinia chrysanthemi infection process in Arabidopsis thaliana leaves. A and B, Transverse thin sections of leaves stained with toluidine blue $24 \mathrm{~h}$ after inoculation with $E$. chrysanthemi (A) or $10 \mathrm{mM} \mathrm{MgSO}_{4}$ (B). Bar $=20 \mu \mathrm{m}$. C, Immunodetection of E. chrysanthemi cells, using a polyclonal antilipopolysaccharide antibody, $24 \mathrm{~h}$ postinoculation (hpi). Bar $=10 \mu \mathrm{m}$. D, Electron micrograph of E. chrysanthemi cells progressing in the intercellular compartment, 24 hpi. Bar $=3.5 \mu \mathrm{m} . \mathbf{E}$ and $\mathbf{F}$, Thin section of leaves immunofluorescently labeled with LM1 antibody to hydroxy-proline-rich glycoproteins (HRGP), $24 \mathrm{~h}$ after inoculation with $10 \mathrm{mM} \mathrm{MgSO}_{4}$ (E) or with E. chrysanthemi $(\mathrm{F})$. Bar $=10 \mu \mathrm{m}$. G, Immunogold labeling with LM1 antibody of an infected leaf reveals HRGP incorporation in the cell wall, 24 hpi. Bar $=1 \mu \mathrm{m}$. H and $\mathbf{I}$, Callose deposition detected with aniline blue in leaves inoculated with $E$. chrysanthemi, 8 hpi (I), not visible in control leaf $(\mathrm{H})$. Bar $=100 \mu \mathrm{m} . \mathrm{b}=$ bacteria, $\mathrm{c}=$ chloroplast, $\mathrm{cd}=\mathrm{callose}$ deposit, $\mathrm{cv}=$ central vacuole, $\mathrm{h}=\mathrm{HRGP}$, is $=$ intercellular space, and $\mathrm{v}=$ vein. 
A

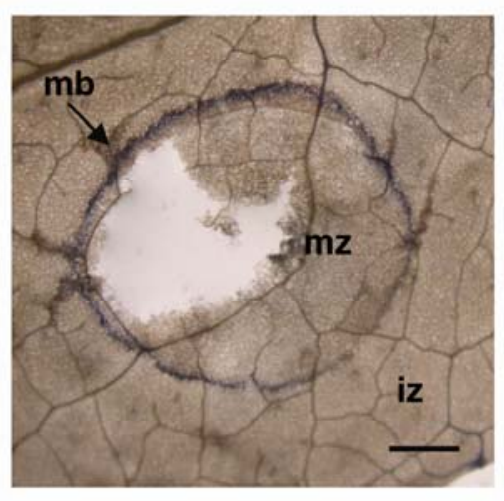

B

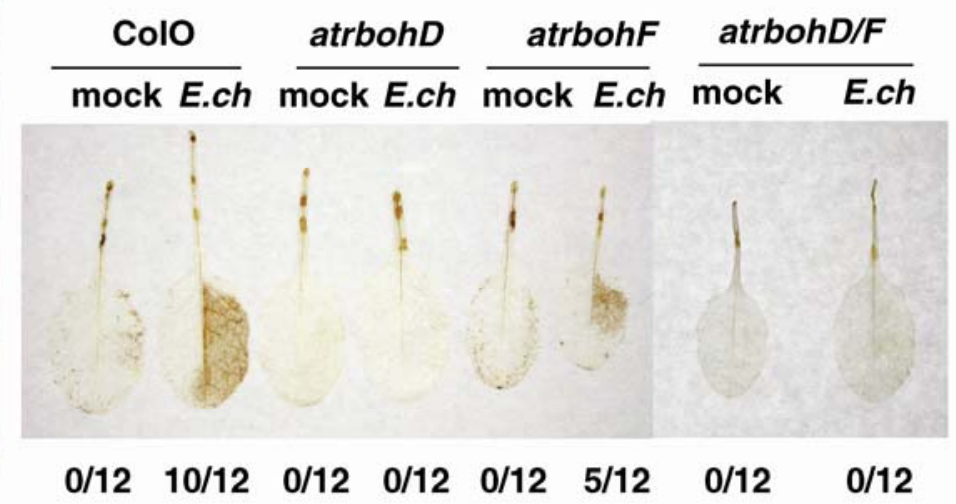

D

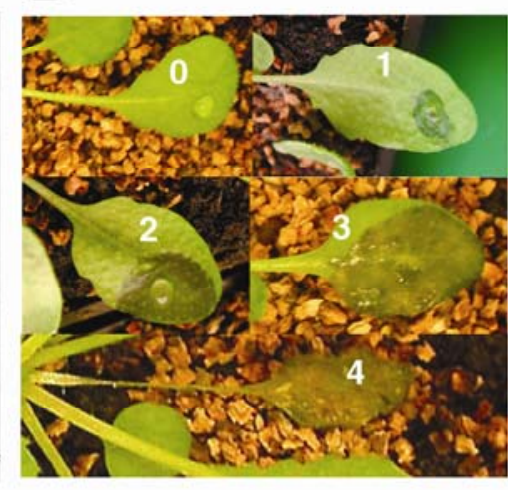

F

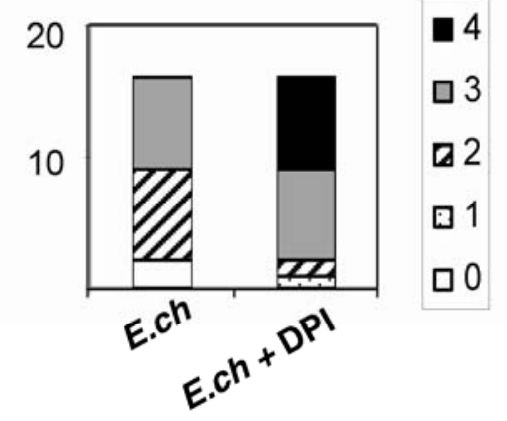

G
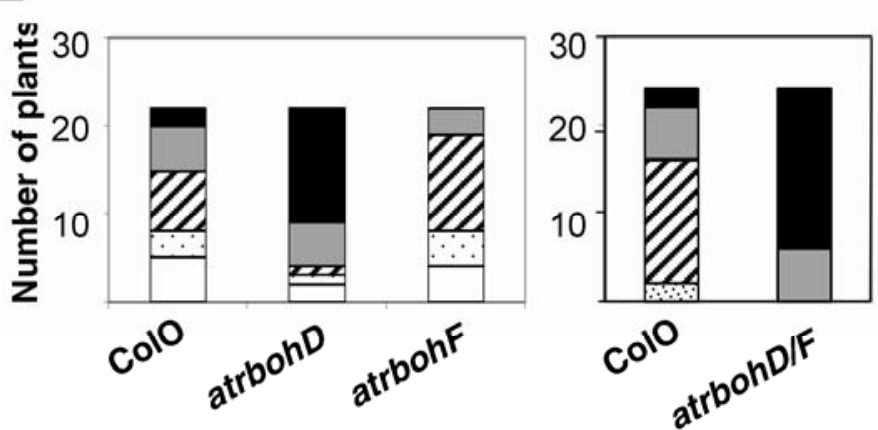

E

$$
\text { mock }
$$

\section{E.ch}
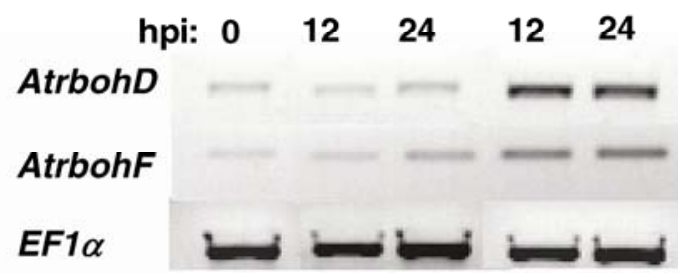

Fig. 2. Oxidative burst caused by Erwinia chrysanthemi on Arabidopsis thaliana and its role in resistance. A, Nitroblue tetrazolium staining showing superoxide ions produced at the border of maceration in leaves inoculated with E. chrysanthemi. Bar = $1 \mathrm{~mm}$. B, DAB (3, 3'-diaminobenzidine) staining showing representative hydrogen peroxide accumulation in leaves infected by E. chrysanthemi $(12$ h postinoculation [hpi], E.ch) in Col-0 and atrboh mutants as indicated. Below each leaf is indicated the number of leaves showing DAB staining out of 12 inoculated leaves. C, Electron micrograph of E. chrysanthemi infected leaf $24 \mathrm{hpi}$, revealing electrodense cerium perhydroxide precipitates $(\mathrm{bar}=1 \mu \mathrm{m})$ absent in diphenylene iodinium $(\mathrm{DPI})$ pretreated leaf $($ bar $=3 \mu \mathrm{m})$ as indicated. D, Symptom severity scale: $0=$ no symptom; $1=$ maceration at the site of inoculation, $2=$ maceration covering about half of the leaf, $3=$ maceration covering the whole leaf, and $4=$ maceration has spread to the rest of the plant. E, Disease severity on $A$. thaliana Col-0, atrbohD and atrbohF single mutants, and atrbohD/atrbohF double mutant $48 \mathrm{~h}$ after $E$. chrysanthemi infection. F, Disease severity on A. thaliana Col-0 pre-treated with $50 \mu \mathrm{M}$ DPI (E.ch + DPI) or mock-treated (E.ch) 48 h after E. chrysanthemi infection. G, Expression of Atrboh genes in E. chrysanthemi (E.ch) or mock-treated leaves as indicated, monitored by reverse transcription-polymerase chain reaction. The constitutively expressed $E F 1 \alpha$ gene is used as an internal control. $\mathrm{b}=$ bacterium, $\mathrm{c}=$ chloroplast, $\mathrm{cp}=$ cerium perhydroxide, is $=$ intercellular space, $\mathrm{iz}=$ intact $\mathrm{zone}, \mathrm{mb}=$ maceration $\mathrm{border}$, and $\mathrm{mz}=\mathrm{macerated} \mathrm{zone}$. 
or double atrbohD and atrbohF mutations (Torres et al. 2002). The presence of the atrbohD mutation resulted in the absence of precipitates (Fig. 2B). With the atrbohF mutation, the reaction was still apparent in half of the infected leaves (Fig. 2B). No precipitate was observed with the double atrbohD/atrbohF mutant in response to $E$. chrysanthemi. These data indicated that the AtrbohD oxidase activity was the main source of ROS production in response to $E$. chrysanthemi infection. We thus tempted to localize the sites of hydrogen peroxide production by EM, using cerium chloride as an indicator. In healthy leaf tissues, we detected the presence of precipitates of cerium perhydroxide only around the veins (data not shown). After infection with the wild-type strain, we observed the appearance of large amounts of precipitates in walls and intercellular spaces colonized by bacteria (Fig. 2C). Pretreatment of inoculated leaves with diphenylene iodinium (DPI), an NADPH oxidase inhibitor, drastically decreased the intensity of this reaction, confirming the importance of the Atrboh enzymes in ROS production (Fig. 2C). Consistent with these observations, we also observed that the transcriptional expression of AtrbohD and AtrbohF genes was induced in A. thaliana leaves inoculated with $E$. chrysanthemi (Fig. 2G).

To further investigate the physiological role of ROS in this disease, we compared the susceptibility to infection of the atrbohD and atrbohF simple mutants and of the atrbohD/atrbohF double mutant to that of the wild-type ecotype. Leaves of 5week-old plants were spot-inoculated with E. chrysanthemi,

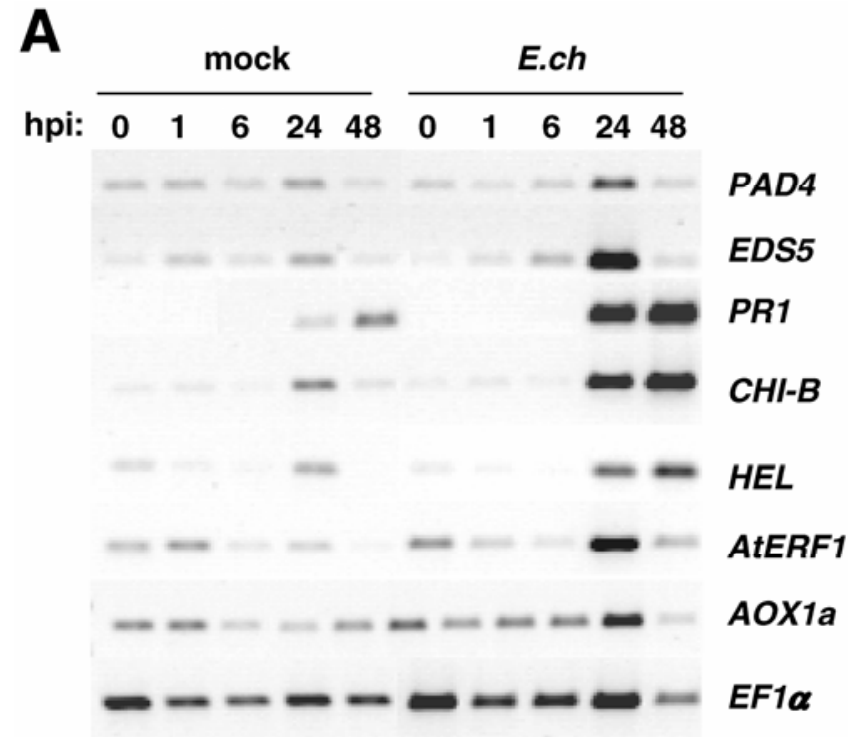

B

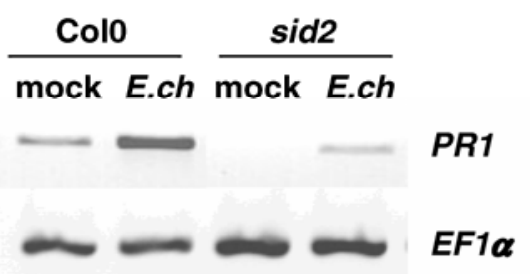

Fig. 3. Expression of defense-related marker genes of the salicylic acid (SA), jasmonic acid (JA), and ethylene (ET) signaling pathways in response to Erwinia chrysanthemi. A, Expression of defense marker genes in E. chrysanthemi $($ E.ch) or mock-treated leaves at indicated times, monitored by reverse transcription-polymerase chain reaction (RT-PCR). B, Expression of the PRI gene 24 h postinoculation in A. thaliana Col- 0 or sid 2 mutant, monitored by RT-PCR. The constitutively expressed $E F 1 \alpha$ gene is used as an internal control. and symptom evolution was scored from 0 to 4 (discussed below and Fig. 2D). Spreading of the symptoms was faster and the number of plants scored at stage 4 was higher in the double-mutant line than in the wild-type (Fig. 2E). This was also the case with the atrbohD simple mutant. In order to confirm that NADPH oxidase activity is required for resistance against E. chrysanthemi, we treated Col-0 leaves with $50 \mu \mathrm{M}$ DPI $2 \mathrm{~h}$ before inoculation. Figure $2 \mathrm{~F}$ shows that DPI-treated plants had more severe symptoms than mock-treated plants.

Altogether, our data show that E. chrysanthemi elicits an oxidative burst on A. thaliana leaves and that this oxidative burst is a defense reaction against this pathogen and contributes to resistance.

\section{Activation of SA and JA or ET signaling pathways:} a fine-tuned response of $A$. thaliana to $E$. chrysanthemi.

Many studies have shown the importance of SA-dependent defense responses in plant-pathogen interactions. Phytohormones JA and ET have also been involved in the triggering of plant defenses necessary to fight pathogens. Genes whose expression is specifically induced by these different signaling pathways in response to pathogens have been described (Glazebrook et al. 2003). In order to investigate the possibility that defense reactions mediated by the three major signaling pathways were activated during infection by $E$. chrysanthemi, we monitored expression of genes used as markers for the different pathways. We used PAD4, EDS5, and PRI as representatives of the SA pathway, $C H I-B$ and $H E L$ as representative genes induced synergistically by ET and JA pathways (Glazebrook et al. 2003), and AtERF1 a gene induced by ET (Fujimoto et al. 2000). We also used the AOXIa gene as a marker of oxidative stress (Simons et al. 1999), since we showed that E. chrysanthemi induced this response in A. thaliana. We monitored expression of these genes by reverse transcription-polymerase chain reaction (RT-PCR) on leaves inoculated with wild-type E. chrysanthemi. Figure $3 \mathrm{~A}$ illustrates the expression patterns of these genes in mock-treated leaves and leaves inoculated with $E$. chrysanthemi at different timepoints after inoculation. We found that the expression of all genes tested was enhanced 24 h after inoculation with $E$. chrysanthemi. These data were repeated several times and always showed the same results with some slight changes in the kinetics of induction. For example, in several of the repeat tests, both PAD4 and EDS5 were found to be induced at $6 \mathrm{hpi}$ (data not shown), which is earlier than $P R 1$ was induced. This is consistent with the role of EDS5 and $P A D 4$ upstream in the SA signaling pathway. No significant induction of any of these genes was ever observed in mocktreated control leaves. Taken together, these data show that following infection of $A$. thaliana by $E$. chrysanthemi, the three major defense pathways are activated in the plant.

In $A$. thaliana, two distinct pathways are thought to lead to the production of SA; in one pathway, SA is synthesized from phenylalanine, while in the other pathway, SA is synthesized from chorismate (Shah 2003). The production of SA from chorismate is dependent on isochorismate synthase encoded by the SID2/ICS1 gene (Nawrath and Métraux 1999; Wildermuth et al. 2001). We investigated whether SA production triggered by $E$. chrysanthemi was SID2/ICSI-dependent. To this end, we compared the accumulation of $P R 1$ transcripts in the sid2 mutant with that in wild-type plants following inoculation with $E$. chrysanthemi. We found that induction of $P R I$ accumulation in response to $E$. chrysanthemi was strongly reduced in the sid2 mutant (Fig. 3B). These results indicate that SA production in $A$. thaliana leaves triggered by E. chrysanthemi attack is for the most part dependent on the SID2/ICS1 pathway.

Our data show that the three major signaling pathways are induced upon infection by E. chrysanthemi. We observed that 
although most infected plants develop symptoms, the progression of bacteria is often stopped before the whole plant is destroyed. In order to determine whether the different defense signaling pathways conferred to the plant a certain level of resistance against $E$. chrysanthemi attack, we compared the susceptibility of $A$. thaliana mutants defective in SA-, JA-, or ETdependent responses with that of the wild-type ecotype Col-0. We used the sid2 mutant, which fails to produce SA (Nawrath and Métraux 1999), the jarl mutant, which does not produce an active form of JA (Staswick et al. 1992, 2002), and the ein2 mutant, which no longer expresses a transmembrane protein required for ethylene perception (Alonso et al. 1999; Guzman and Ecker 1990). Plants were infected with E. chrysanthemi wild-type cells, and symptom evolution was scored from 0 to 4 as described above. We found no significant difference between the sid2 mutant and wild-type plants in terms of number of plants affected and severity of symptoms (Fig. 4), suggesting that the SA pathway is not involved in resistance against $E$. chrysanthemi. Concerning the jarl and ein 2 mutants, we found an increased number of plants with the highest degree of symptom (scored 3 and 4) as compared with wild-type plants (Fig. 4).

Our results show that $A$. thaliana expresses SA-, JA-, and ETdependent defense reactions in response to $E$. chrysanthemi infection, although only JA- and ET-dependent pathways appear to have some efficiency against $E$. chrysanthemi invasion.

\section{Oxidative burst and SA-mediated defense are triggered independently.}

Several investigations have revealed the existence of a positive regulatory loop between SA production and $\mathrm{H}_{2} \mathrm{O}_{2}$ accumulation during the establishment of plant resistance in response to pathogen attack (Klessig et al. 2000; Leon et al. 1995; Shirasu et al. 1997; Summermatter et al. 1995). Because Atr-
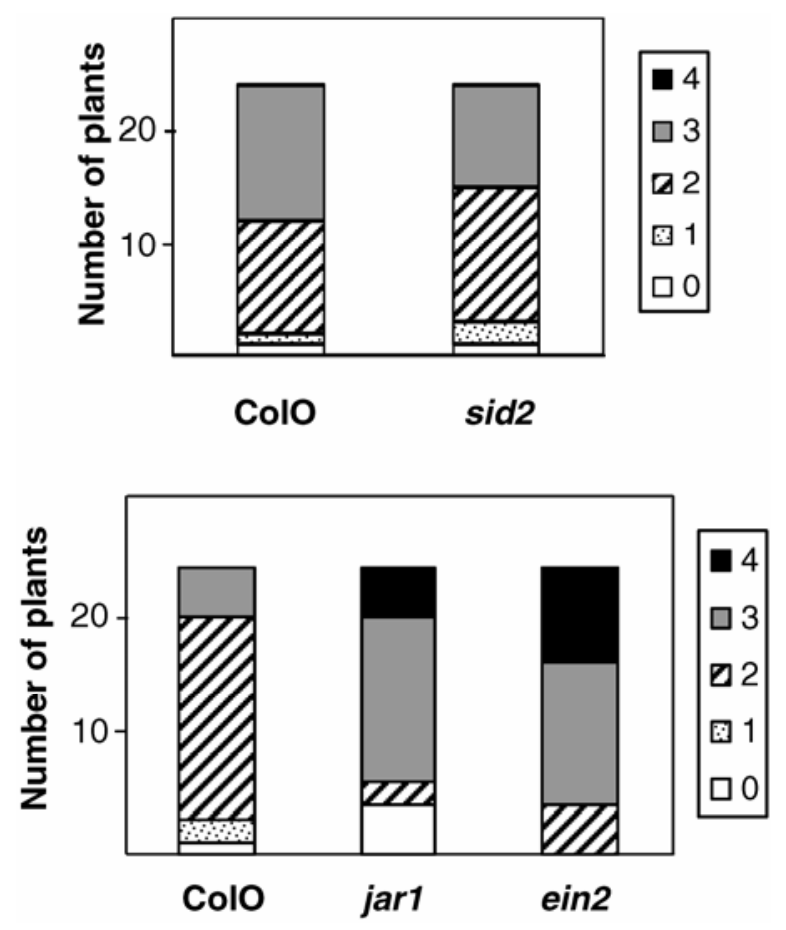

Fig. 4. Disease severity on Arabidopsis thaliana defense signaling mutants. Symptoms are shown on Col-0 and mutants as indicated at $48 \mathrm{~h}$ postinoculation. Symptom severity scale: $0=$ no symptom, $1=$ maceration at the site of inoculation, 2 = maceration covering about half of the leaf, $3=$ maceration covering the whole leaf, and $4=$ maceration has spread to the rest of the plant.
bohD is induced by $E$. chrysanthemi and involved in resistance to this bacterium, we asked whether there existed connections between the AtrbohD and AtrbohF-dependent ROS production and the SA pathway activation by E. chrysanthemi. We first analyzed the induction by E. chrysanthemi of the SA pathway in the atrbohD/atrbohF double mutant. Figure 5A shows that the SA-dependent PRI gene is normally induced by E. chrysanthemi in the atrbohD/atrbohF double mutant $24 \mathrm{~h}$ after infection. We then analyzed $\mathrm{H}_{2} \mathrm{O}_{2}$ production by DAB staining in the SA-deficient sid2 mutant. Figure $5 \mathrm{~B}$ shows that the staining is identical in wild-type and sid2 leaves, indicating that $\mathrm{H}_{2} \mathrm{O}_{2}$ accumulates to similar levels in sid2 and wild-type plants in response to E. chrysanthemi. Altogether, our data show that local $\mathrm{H}_{2} \mathrm{O}_{2}$ production and $\mathrm{SA}$ pathway activation in response to $E$. chrysanthemi attack are not linked events.

\section{Role of bacterial pectinases}

in the triggering of host defense.

As pectin-degrading enzymes are able to generate elicitoractive oligogalacturonides (De Lorenzo et al. 1991; NormanSetterblad et al. 2000), we determined the implication of the $E$. chrysanthemi enzymes in the triggering of host defense. For this purpose, we analyzed the responses induced by the out $C$ mutant of E. chrysanthemi, which lacks a functional T2SS. This mutant did not produce visible degradation of pecto-cellulosic structures after infection; however, it was still able to colonize the intercellular spaces (Fig. 6A) and to grow during the first two days following inoculation to the same extent as wild-type bacteria (Fig. 6B).

Concerning cell-wall defenses, we found that both callose and HRGP accumulated in A. thaliana leaves after infection with the outC mutant of E. chrysanthemi (Fig. 6C and D) to

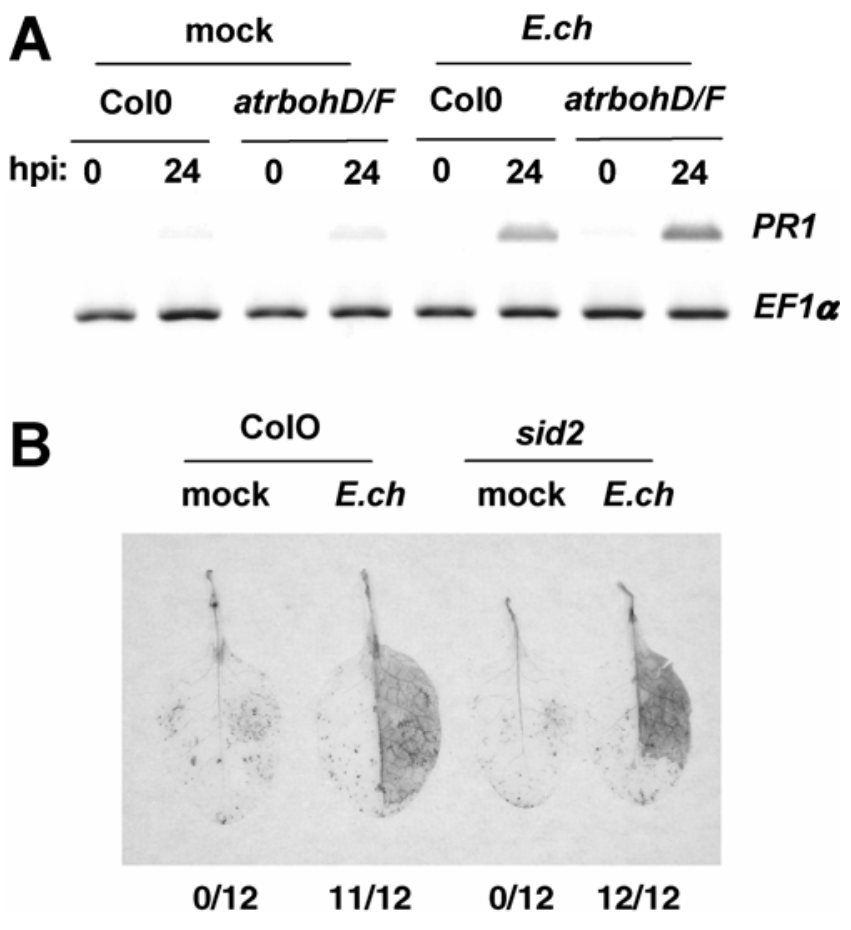

Fig. 5. Relationship between salicylic acid and reactive oxygen species signaling in Arabidopsis thaliana infected by Erwinia chrysanthemi. A, Expression of the PRI gene in E. chrysanthemi (E.ch) or mock-treated leaves at indicated times, monitored by reverse transcription-polymerase chain reaction, in Col-0 or atrbohD/atrbohF double mutant. The constitutively expressed $E F 1 \alpha$ gene is used as an internal control. B, DAB (3, 3'diaminobenzidine) staining in Col-0 or sid 2 mutant $12 \mathrm{~h}$ postinoculation with E. chrysanthemi. Numbers below each leaf indicate the number of leaves showing DAB staining out of 12 inoculated leaves. 
the same extent as in response to wild-type bacteria (Fig. 1F and I). These results indicate that the T2SS and T2SS-secreted proteins are not involved in the triggering of HRGP and callose. The production of $\mathrm{H}_{2} \mathrm{O}_{2}$ in response to E. chrysanthemi also seemed independent of T2SS-secreted proteins (Fig. 7A). Indeed, the DAB staining was equivalent in response to wildtype and outC bacteria. Surprisingly however, we found that the outC mutant induced only slightly the accumulation of the AtrbohD and AtrbohF transcripts (Fig. 7B). This could be explained by the fact that the low level of AtrbohD and AtrbohF gene induction in response to the outC mutant is sufficient for the production of $\mathrm{H}_{2} \mathrm{O}_{2}$ seen in Figure $7 \mathrm{~B}$ or that AtrbohD and AtrbohF are regulated post-translationally. It is also possible, however, that the DAB staining is not sensitive enough to detect slight differences in the accumulation of $\mathrm{H}_{2} \mathrm{O}_{2}$ in response to wild-type and outC mutant bacteria.

RT-PCR analysis showed that the expression of the different defense marker genes was strongly affected by the outC mutation (Fig. 7C). Several marker genes were not at all induced by the E. chrysanthemi outC mutant (EDS5, PAD4, and AtERF1), while others showed a reduced accumulation by 48 hpi $(P R I$ and $C H I-B)$ relative to the wild-type strain. Our results indicate that $E$. chrysanthemi pectinases secreted by the Out secretion system are involved in the triggering of the SA as well as the JA and ET pathways.

In order to confirm the role of E. chrysanthemi pectindegrading enzymes in the induction of these defense genes, we analyzed the effect of individual pectate lyases on gene expression by RT-PCR. The extracellular pectate lyase activity of $E$. chrysanthemi results from the mutual action of at least eight enzymes, PelA to PelE, PelI, PelL, and PelZ. We chose PelB, PelI, and PelL enzymes because they are representative members of the three families of polysaccharide lyases present in $E$. chrysanthemi, among the sixteen families defined (CAZY web site). A. thaliana leaves were infiltrated with purified enzyme resulting in leaf maceration $24 \mathrm{~h}$ after treatment in the case of PelI and PelB. PelL induced no symptoms (data not shown). Figure 7D shows the level of induction of A. thaliana defense genes $24 \mathrm{~h}$ after treatment. The SA-dependent PRI gene was induced by all three enzymes. Both ET- and JA-dependent $C H I-B$ gene and AOXIa were strongly induced by PelI and PelB but not by PelL. We did not detect any increase in the expression of PAD4 and EDS5 in response to any of the enzymes tested.

Altogether, our data show that E. chrysanthemi pectinases participate in the activation of SA, JA, and ET signal transduction pathways leading to reduced defense gene activation in the out mutant. On the other hand, the Out secretion system of E. chrysanthemi does not seem to be involved in triggering cell-wall-based defenses. The accumulation of $\mathrm{H}_{2} \mathrm{O}_{2}$ in response to bacterial attack does not require a functional T2SS, even though this secretion system seems to regulate AtrbohD and AtrbohF gene expression.

\section{DISCUSSION}

In this study we addressed the question whether A. thaliana, as a susceptible host, expresses immune reactions in response to $E$. chrysanthemi infection.

As a primary approach, we investigated the infection process of E. chrysanthemi in A. thaliana leaves and found that it resembles that observed in African violet (Murdoch et al. 1999). Indeed, the bacteria were mainly present in the intercellular spaces of cortical parenchyma and never reached vascular tissues, a fact that is consistent with the callose deposition observed along the leaf veins. Furthermore, bacteria were visible in nondegraded zones close to the maceration, indicating that they can survive in the host before producing their pectinases.
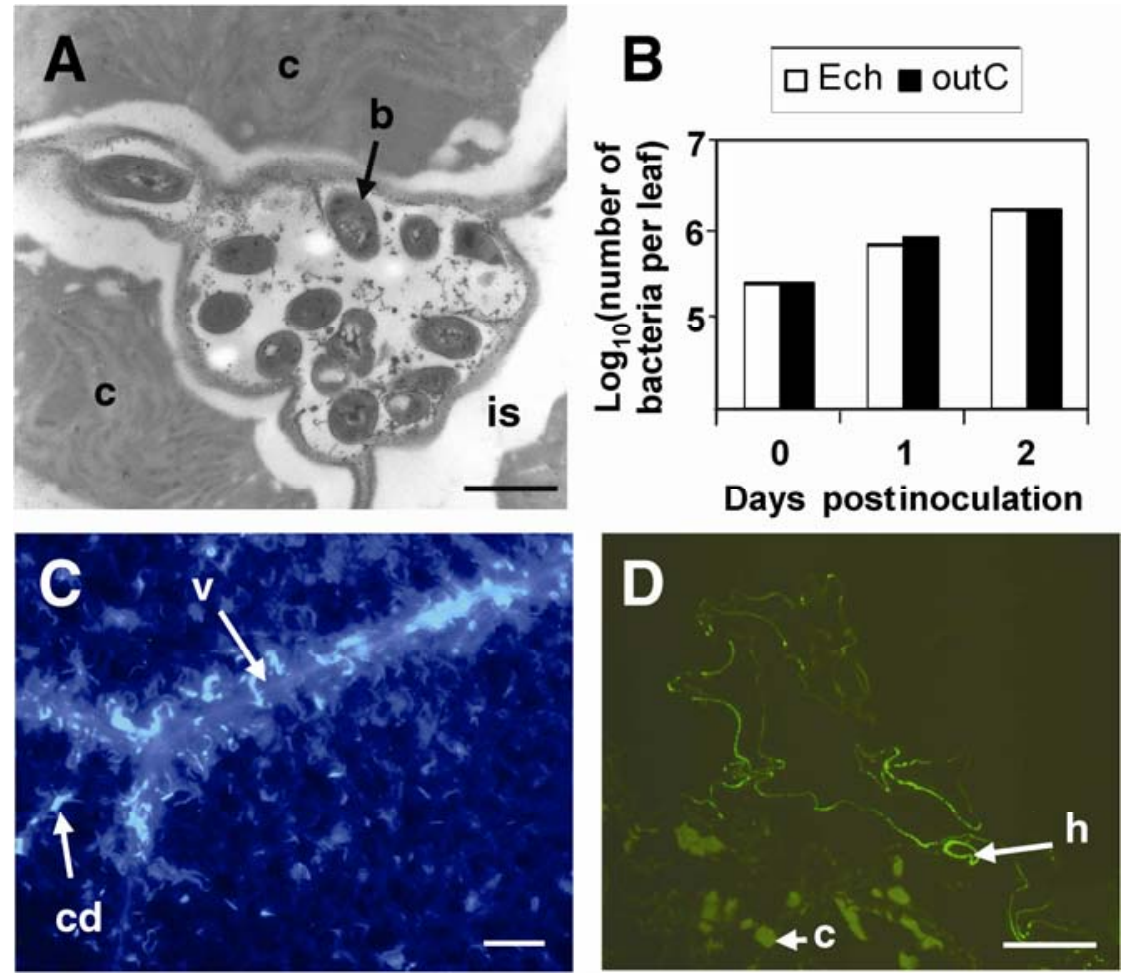

Fig. 6. Role of Erwinia chrysanthemi type II secretion system in cell-wall defense activation and plant colonization. A, Electron micrograph of E. chrysanthemi outC mutant cells progressing in the intercellular compartment $24 \mathrm{~h}$ postinoculation (hpi). Bar $=1 \mu \mathrm{m}$. B, Growth of $E$. chrysanthemi wild type (white bars) and outC mutant (black bars). C, Callose deposition detected with aniline blue in leaves inoculated with $E$. chrysanthemi outC mutant 8 hpi. Bar $=100$ $\mu \mathrm{m}$. D, Thin section of leaves immunofluorescently labeled with LM1 antibody to hydroxy-proline-rich glycoproteins 24 h after inoculation with $E$. chrysanthemi outC mutant. Bar $=10 \mu \mathrm{m} . \mathrm{b}=$ bacteria, $\mathrm{c}=$ chloroplast, $\mathrm{cd}=$ callose deposit, $\mathrm{h}=\mathrm{HRGP}$, is $=$ intercellular space, and $\mathrm{v}=$ vein. 
This asymptomatic phase is reminiscent of the latency period, during which bacteria can persist in plant tissues, described in E. chrysanthemi natural infections (Pérombelon 2002). Ahead of the symptoms in the bacterial-colonized asymptomatic area, we found that cell-wall defenses including apposition of HRGPs and callose deposition were expressed. The ultrastructural analysis (Fig. 1) shows groups of bacteria trapped in intercellular spaces, which are surrounded by plant walls accumulating HRGPs. Interestingly, in similar zones close to the plasma membrane, we detected the accumulation of cerium perhydroxides precipitates, indicating the formation of hydrogen peroxide and the possible cross-linking of HRGPs, a reaction able to strengthen the cell-wall barrier and to limit bacterial progression (Lamb and Dixon 1997).

The production of hydrogen peroxide as part of the oxidative burst is one of the common host responses to pathogens. A sustained phase of ROS production correlates to disease resistance and is involved in the control of cell death in incompatible interactions leading to HR (Torres et al. 2002; 2005; 2006). In plant-microbe interactions, ROS can be produced from several sources, including the plasma-membrane-associated NADPH oxidases AtrbohD and AtrbohF and cell-wall peroxidases (Torres et al. 2006). We demonstrated by different staining methods that E. chrysanthemi induces the production of ROS that accumulate to high levels 24 hpi. The occurrence of this oxidative burst does not fit the common scheme described in compatible interactions, in which only a low-amplitude and transient phase of ROS production usually takes place (Grant and Loake 2000). It resembles more (Fig. 2) the oxidative phase caused by the mammalian phagocyte NADPH oxidase during infection by enteric bacteria (Vasquez-Torres et al. 2000). Indeed, we found that the ROS production is mainly due to a NADPH oxidase functional homolog encoded by the AtrbohD gene. The lack of a functional AtrbohF gene only partially resulted in reduced levels of ROS. AtrbohD and AtrbohF enzymes are known to generate superoxide anions, and the results obtained by NBT staining are in agreement with the proposal that an NADPH oxidase activity represents the main source of ROS in this pathosystem. Furthermore, absence of a functional AtrbohD gene in the host increases the susceptibility to E. chrysanthemi, indicating that the AtrbohD gene is involved in resistance to infection by this bacterium. Consistent with the minor role of the AtrbohF gene in ROS production is that the implication of this gene in resistance also appeared less pronounced. Thus, the oxidative burst induced by $E$. chrysanthemi reflects an antimicrobial reaction from the host, rather than being a strategy of infection as reported for the necrotrophic fungus Botrytis cinerea (Govrin and Levine 2000). These data explain why E. chrysanthemi needs to possess several types of antioxidant systems to complete its infectious cycle. The AtrbohD enzyme was also found to be the main source of ROS in A. thaliana in response to the avirulent Pseudomonas syringae pv. tomato DC3000 carrying the avrRpml gene (Torres et al. 2002). This enzyme can thus be the source of ROS in two different types of interactions, one leading to $\mathrm{HR}$ and the other one to basal immunity (Nürnberger

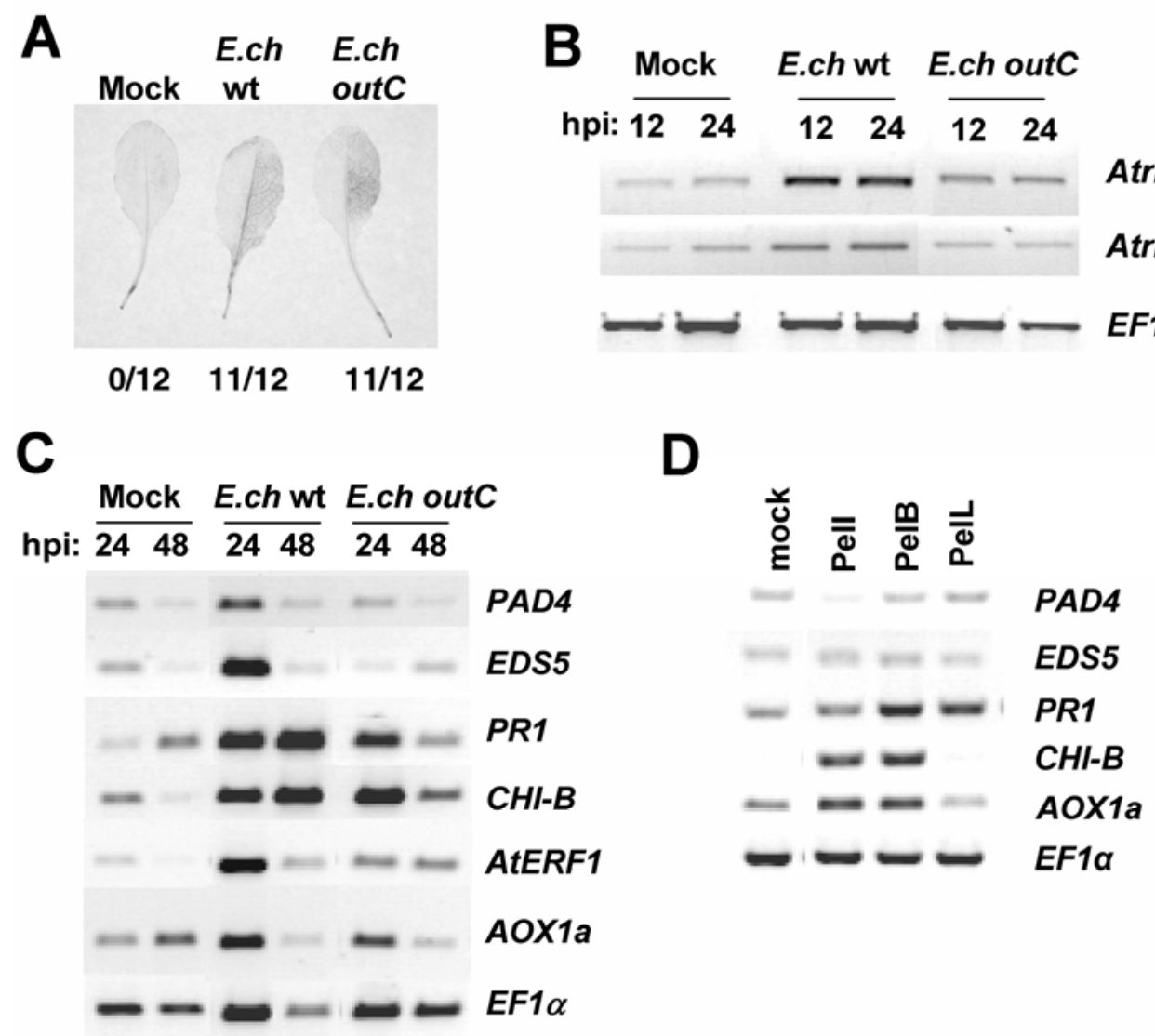

Fig. 7. Role of Erwinia chrysanthemi type II secretion system and pectate lyases in plant defense induction. A, DAB (3, 3'-diaminobenzidine) staining of leaves $12 \mathrm{~h}$ after inoculation with E. chrysanthemi wild-type strain or outC mutant. Numbers below each leaf indicate the number of leaves showing DAB staining out of 12 inoculated leaves. B, Expression of atrbohD and atrbohF in response to outC mutant at the indicated times. C, Expression of defenserelated marker genes in response to $E$. chrysanthemi outC mutant. D, Expression of defense-related marker genes 24 h after infiltration with purified $E$. chrysanthemi pectate lyases as indicated. Gene expression was monitored by reverse transcription-polymerase chain reaction. The constitutively expressed $E F 1 \alpha$ gene is used as an internal control. 
et al. 2004). However, the expression of both AtrbohD and AtrbohF gene is induced by infection with E. chrysanthemi, indicating the activation of a transcriptional program following perception of this bacterium. Again, the accumulation of AtrbohD transcripts was higher than that observed for the AtrbohF gene. Thus, it is possible that ROS production mediated both by AtrbohD and AtrbohF genes in response to $E$. chrysanthemi is part of a signaling process that remains to be determined.

To establish the importance of SA, ET, and JA defense signaling molecules in the $E$. chrysanthemi-A. thaliana pathosystem, we monitored the expression of genes specific to each signaling pathway and compared the disease severity in mutant lines affected in these pathways to the parent Col-0. While no difference in susceptibility was observed between the SA-deficient sid2 mutant and Col-0, both the ET- and JA-insensitive ein2 and jarl mutants, respectively, developed more severe symptoms than the wild type did. However, in terms of gene expression, our data show that the three pathways are activated by the bacterium and expression of the SA pathway is dependent on the integrity of the SID2 isochorismate synthase-encoding gene. This indicates that although the SA pathway is activated, the SA produced via SID2 is either insufficient or not necessary for resistance to E. chrysanthemi. These two hypotheses can be tested by analyzing the susceptibility of $c p r$ mutants (Bowling et al. 1997) or SA-treated plants to E. chrysanthemi. In contrast, the enhanced susceptibility of the ein2 and jarl mutants suggests that ET and JA are mediators for a certain level of resistance against the bacterium and confirms that $E$. chrysanthemi falls into the necrotrophic lifestyle of pathogens, as described by Glazebrook (2005). These results are reminiscent of those reported for the soft-rotting bacterium E. carotovora subsp. carotovora SCC3193, which multiplied at a higher level in ET-and JA-insensitive ein2 and coil mutants, respectively, which was not observed in $n a h G$ transgenic plants that do not accumulate SA (Norman-Setterblad et al. 2000). In their study however, the authors found a very weak activation of the SA marker PRl, whereas the ET and JA pathways were strongly activated by bacterial cells or their culture filtrates containing pectinases. These data indicate that E. carotovora subsp. carotovora SCC3193 and E. chrysanthemi 3937, although closely related in their mode of infection, are not perceived in similar ways by the same plant species. It is possible that E. chrysanthemi produces elicitors that activate the SA pathway, which can potentially downregulate the JA pathway unfavorable to the bacterial growth (Reymond and Farmer 1998).

Pectinases were shown to activate defenses on tobacco and A. thaliana plants (Norman-Setterblad et al. 2000; Palva et al. 1993). Their action is most likely due to the oligogalacturonides they produce, which act as endogenous elicitors (Kita et al. 1996; Palva et al. 1993; Ryan and Farmer 1991). In order to address the question of the role played by E. chrysanthemi pectinases in triggering defense responses, we used a bacterial mutant affected in the biogenesis of the Out system and thus unable to secrete cell-wall-degrading enzymes. This mutant was still able to colonize the intercellular spaces, but infection resulted in reduced expression of the genes representative of the SA and ET or JA pathways compared with the wild-type strain, suggesting that pectinases are involved in defense activation. The defense reactions were not completely abolished after infection with the out mutant (Figs. 6 and 7), which indicates that T2SS effectors are not the only factors causing activation of this line of defense. However, leakiness of out mutant cells could be responsible, at least partially, for the residual defense-gene response observed. This possibility, although unlikely because of the lack of visible degradation of pecto- cellulosic structures after infection by this mutant, must not be totally excluded. Using an out-deficient mutant has the advantage of abolishing the secretion of pectin-degrading enzymes. However, another type of protein that transits through the Out system and might elicit defenses is the avirulence-like protein AvrL (Kazemi-Pour et al. 2004). Therefore, we investigated the effect caused by purified PelB, PelI, and PelL representing the different families of pectate lyase isozymes (CAZY web site). We found that the SA pathway was activated by these three enzymes, whereas the ET and JA pathways were only activated by PelB and PelI. Surprisingly, PAD4 and EDS5, which have been shown to be required for SA signaling and PR1 activation (Glazebrook et al. 2003), did not seem to be activated by Pels. This could be due to a low level of induction by the Pels, undetected by RT-PCR but sufficient to trigger the signaling leading to the induction of $P R I$ expression. Another explanation could be that $P R I$ expression is induced by Pels through EDS5- and PAD4-independent signaling. In that case, the induction of the expression of EDS5 and PAD4 by the wild-type bacteria would be triggered by other T2SS effectors than Pels.

The different sizes of oligogalacturonides produced by Pels could explain the differential pattern of defense responses described above. Indeed, both PelB and PelI have a strong maceration capacity and mainly generate unsaturated dimers and trimers from polygalacturonate, whereas PelL, less active in terms of maceration, produces tetramers and pentamers (Roy et al. 1999). The common pattern of defense gene induction by PelB and Pell could be due in part to the release of unsaturated dimers but also to the large amounts of oligogalacturonides generated by these enzymes. It is then understandable that when several pectinases are produced by the wild-type bacterium, the SA, ET, and JA pathways are collectively activated. Perhaps, the more likely explanation for the complex interplay that governs pectinase production and defense elicitation is a system of on-off switches controlled by the bacteria. The pathogen needs pectinases to progress inside plant tissues, but when the plant perceives the endogenous elicitors, it is possible that the bacterial cells somehow detect this reaction and repress the production of the enzymes. If the signal disappears, the pectinase genes are activated again. A very complex regulation of pectinases encoding genes in response to environmental signals does exist (Robert-Baudouy et al. 2000). The diversity of the regulators involved can lead to differential production of these enzymes in the host. The majority of these regulators are repressors, suggesting that the bacteria need to strongly downregulate the expression of these enzymes under certain circumstances. Pectinase gene repression is probably crucial at the onset of infection, as for instance, in asymptomatic tissues when the bacteria escape the barriers of defense, cell-wall strengthening, and ROS attack. Interestingly, pectinases do not seem to be required for the bacterium to induce ROS production, even though they trigger SA signaling. This fact fits with the observation that ROS and SA act independently in the defense signaling cascade triggered by E. chrysanthemi. Other bacterial elicitors such as T3SS or lipopolysaccharide (LPS) could be responsible for ROS induction by outC mutant. Indeed, $E$. amylovora T3SS and LPS from Xanthomonas campestris pv. campestris and Burkholderia cepacia were shown to induce ROS accumulation (Gerber et al. 2004; Meyer et al. 2001; Venisse et al. 2001).

Because pectinases are like double-edged swords (Jha et al. 2005), the fine control of their production is one of the major points the bacteria have to deal with during infection. It will be worthwhile exploiting the knowledge of their complex regulatory network to elucidate their mode of action in the host. This regulatory network should confer on the bacteria the ability to 
integrate plant signals and activate virulence factors and suppressors of plant defenses.

\section{MATERIALS AND METHODS}

\section{Plant growth and inoculation conditions.}

A. thaliana seeds from the Col-0 and Ws ecotypes were obtained from the INRA Versailles collection. The sid2-1 mutant was donated by J-P. Métraux (Fribourg, Switzerland). Seeds of ein2-1 (Guzman and Ecker 1990) and jarl-1 (Staswick et al. 1992) mutants were provided by the Nottingham Arabidopsis Stock Center (Scholl et al. 2000). Simple and double atrbohD and atrbohF mutants (Torres et al. 2002) were provided by J. Dangl (Chapel Hill, NC, U.S.A.). The seeds were sown in nonsterile soil and then vernalized by incubation for 2 days at $4^{\circ} \mathrm{C}$. The resulting seedlings were allowed to grow for two weeks and were then potted individually into separate pots. The plants were allowed to grow for a further three weeks before inoculation. The 5-week-old plants were heavily watered and covered with a transparent plastic $16 \mathrm{~h}$ before inoculation. This stimulated the stomata opening, thereby facilitating inoculation. The cover was kept in place throughout the assay to maintain high-moisture conditions. Plants were always subjected to an 8-h light and 16$\mathrm{h}$ dark cycle at $19^{\circ} \mathrm{C}$, with $70 \%$ relative humidity.

\section{Bacterial strains and pectate lyases purification.}

The wild-type strain E. chrysanthemi 3937 (our collection) was isolated from Saintpaulia ionantha H. Wendl. (African violet). The isogenic out mutant strain contains the mutation outC::uidA (kanamycin resistant) (Condemine and RobertBaudouy 1995). E. chrysanthemi strains were grown in LuriaBertani medium (Miller 1972). Bacterial strains were stored at $-70^{\circ} \mathrm{C}$ in liquid cultures containing $40 \%$ glycerol. For plant inoculations, the bacterial inoculum was prepared as follows: an aliquot of the glycerol stock culture was streaked on agar medium (with antibiotics, if necessary) and was grown for $48 \mathrm{~h}$ at $30^{\circ} \mathrm{C}$ with a single colony and then was used to inoculate a liquid culture. After $8 \mathrm{~h}$ of growth, $100 \mu \mathrm{l}$ of the culture was plated on agar medium without antibiotic and was allowed to grow overnight. The bacteria were then suspended in the appropriate solution and inoculum density was adjusted to the value mentioned in each experiment. The pectate lyases PelB, PelI, and PelL were purified to homogeneity from recombinant E. coli BL21 strains as described previously (Jenkins et al. 2004; Shevchik et al. 1997a and b).

\section{Plant inoculations.}

For the scoring of symptoms, bacterial counting, superoxide anion detection, and cerium chloride-mediated detection of hydrogen peroxide, a small hole was made with a needle within the leaf, and then, $5 \mu \mathrm{l}$ of a bacterial suspension at a density of $5 \times 10^{8} \mathrm{CFU} / \mathrm{ml}$ made up in $50 \mathrm{mM}$ potassium phosphate buffer ( $\mathrm{pH} 7$ ) was spotted. Symptom severity was scaled (Fig. 2) as follows: 0, no symptom; 1, maceration at the site of inoculation; 2, maceration has spread to about half of the leaf; 3 , maceration has spread to the whole leaf; and 4, maceration has started to spread to the rest of the plant. Bacterial counting was performed by grinding infected leaves in 10 $\mathrm{mM} \mathrm{MgSO}_{4}$, using a pestle and sterile sand. The resulting suspension was used for serial dilutions followed by plating on minimal medium. For RNA extractions, DAB staining, callose detection, electron microscopy, and immunofluorescence, leaves were syringe-infiltrated with bacterial suspensions at a concentration of $10^{7} \mathrm{CFU} / \mathrm{ml}$ in $10 \mathrm{mM} \mathrm{MgSO}$ or with Pels at a concentration of $20 \mu \mathrm{g} / \mathrm{ml}$ in $10 \mathrm{mM}$ Tris- $\mathrm{HCl}$ (pH8), using a syringe without a needle. All data are representative of three independent inoculation experiments.
RNA extraction and RT-PCR analysis.

For RNA extraction, infiltrated leaves were cut off at the indicated times, were immediately frozen in liquid nitrogen, and were then stored at $-70^{\circ} \mathrm{C}$. Total RNA was prepared by phenol-chloroform extraction followed by $\mathrm{LiCl}$ precipitation, as described by Verwoerd and associates (1989). For RT-PCR analysis, first-strand cDNA was synthesized using Superscript reverse transcriptase (Invitrogen, Carlsbad, CA, U.S.A.) from $1 \mu \mathrm{g}$ of DNase-treated (Invitrogen) total RNA in a $20-\mu \mathrm{l}$ reaction volume. cDNA was precipitated and resuspended in $50 \mu \mathrm{l}$ of water, and then, $1 \mu \mathrm{l}$ of the cDNA was subjected to PCR in a $20-\mu \mathrm{l}$ reaction volume. PCR runs were of 25 to 30 cycles, each cycle consisting of $94^{\circ} \mathrm{C}$ for $30 \mathrm{~s}, 52$ to $55^{\circ} \mathrm{C}$ for $30 \mathrm{~s}$, and $72^{\circ} \mathrm{C}$ for $1 \mathrm{~min}$, with a final step of $72^{\circ} \mathrm{C}$ for $2 \mathrm{~min}$ to complete polymerization. The gene-specific primers used in this analysis were as follows: AOX1a-F (At3g22370), 5'-ACA TCT GCT TGG ATA TGG ACT AGA G-3'; AOX1a-R, 5'-TAA GTA ACC AAG GAA ATA AGC GTT G-3'; AtERF1-F (At4g17500), 5'-CAA TCT TGT GTA ACC GGT CAG AGC3'; AtERF1-R, 5'-CAC CGT CAA TCC CTT ATC CAT TCC3'; AtrbohD-F (At5g47910), 5'-CTA CTG GGT GAC TAG GGA ACA AGG-3'; AtrbohD-R, 5'-TTA ATC TAG AAG TTC TCT TTG TGG AA; AtrbohF-F (At1g64060), 5'-TTA GGG AAG GAG CTT AGC AAA CTA-3'; Atrboh- $F$-R, 5'-CTA ATC ACA TGG ACC TTA TCA ACG-3'; EDS5-F (At4g39030), 5' GGG AAC AGA TGA AAG AGA TAG TGA A-3'; EDS5-R, 5'-ATT AGT CCA CAA ACC AAT CCA ATA A-3'; EFla-F (At1g07940), 5'-ATG CCC CAG GAC ATC GTG ATT TCA T3'; EFla -R, 5'-TTG GCG GCA CCC TTA GCT GGA TCA3'; HEL-F (At3g04720), 5'-GAA GAT CAG ACT TAG CAT AAC CAT CA-3'; HEL-R, 5'-ATC GGT GTC TAT TTG ATT GAA CAT T-3'; PAD4-F (At3g52430), 5'-TTT AAA GTG AAC ATG AGT CGC ATA A-3'; PAD4-R, 5'-ATC AAC AAC CAT CTC AAT TTC ATT T-3'; PRl-F (At2g14610), 5'-CTG GCT ATT CTC GAT TTT TAA TCG-3'; and PRl-R, 5'-TCC TGC ATA TGA TGC TCC TTA TTG-3'.

\section{ROS detection.}

The detection of superoxide was performed using NBT staining. After spot inoculation with the bacterial suspension, leaves were stained for $15 \mathrm{~min}$ in $0.05 \mathrm{M}$ sodium phosphate buffer ( $\mathrm{pH}$ 7.4) containing $0.1 \%$ NBT (Sigma, St. Louis) at room temperature. Leaves were then transferred in $96 \%$ ethanol to stop the reaction and to remove chlorophyll. Observations were done with a binocular microscope SZX12 (Olympus Corporation, Tokyo). To detect $\mathrm{H}_{2} \mathrm{O}_{2}$ in leaves, we used the DAB coloration method described by Torres and associates (2002). Histochemical detection of $\mathrm{H}_{2} \mathrm{O}_{2}$ with cerium chloride (Acros Organics, Morris Plains, NJ, U.S.A.), leading to the formation of electron-dense precipitates of cerium perhydroxydes, was carried out according to the procedure described by Bestwick and associates (1997). Specific conditions for NADPH oxidase inhibitor treatment were $2 \mathrm{~h}$ preincubation in $50 \mu \mathrm{M}$ DPI (Sigma).

\section{Microscopy, immunolabeling, and callose staining.}

For light microscopy (LM) and EM, small fragments of leaves were sampled from the infected zone $24 \mathrm{hpi}$. In case of leaf maceration, they were collected at the boundary between the macerated and the nonmacerated zone. Fragments of leaves inoculated with $10 \mathrm{mM} \mathrm{MgSO}_{4}$ were collected as control. Samples were fixed for $3 \mathrm{~h}$ in a solution consisting of $4 \%$ paraformaldehyde, $1 \%$ glutaraldehyde in $0.05 \mathrm{M}$ piperazine-N, N'bis(2-ethanesulfonic acid) (PIPES) buffer, $\mathrm{pH} 7.3$, under intermittent vacuum. They were washed four times in the same buffer and were dehydrated in a graded ethanol series before embedding in a LR White resin (The London Resin Co., Hamp- 
shire, U.K.). For LM, transverse semithin $(0.5 \mu \mathrm{m})$ sections were cut with a diamond knife (Diatome histo, Bienne, Switzerland). Some sections were stained with $0.1 \%$ toluidine blue (Touzard \& Matignon, Paris) for $3 \mathrm{~min}$, and then were washed, air dried, and mounted in Eukitt medium (0. Kindler, Freiburg, Germany). They were then observed with a Zeiss Axiophot light microscope (Zeiss, Oberkochen, Germany). For EM, ultrathin sections of $90 \mathrm{~nm}$ were made with a diamond knife (Diatome, Biel, Switzerland) and were collected on nickel or gold grids. The PATAg reaction was performed on ultrathin sections collected on gold grids. Grids were treated as described by Murdoch and associates (1999). After treatment, they were observed with a Philips 400 transmission electron microscope.

For immunolabeling of cell-wall components, we used the monoclonal LM1 antibodies that have a high affinity for an epitope of HRGP (Smallwood et al. 1995). For LM, semithin transverse sections were treated for $5 \mathrm{~min}$ with phosphatebuffered saline with bovine serum albumin buffer containing $0.01 \%$ Tween-20 (PBSB-T) and were transferred to rabbit serum diluted 1:30 in PBSB-T for $20 \mathrm{~min}$. They were washed (four times for $10 \mathrm{~min}$ ) and were incubated overnight at $4^{\circ} \mathrm{C}$ with LM1 (diluted 1:30 in PBSB-T) antibodies. After four washes for $10 \mathrm{~min}$ with PBSB without Tween, the sections were incubated at room temperature with a rabbit anti-rat immunoglobulin $(\mathrm{IgG})$ labeled with fluorescein isothiocyanate (FITC) diluted 1:300 in PBSB, in the dark. The slides were washed six times for $10 \mathrm{~min}$ each with PBSB, were rinsed with distilled water, and were then mounted in one drop of Vectashield medium. Fluorescence was observed with a Zeiss microscope (excitation filter for 450 to $490 \mathrm{~nm}$ wavelength, and barrier filter for $520 \mathrm{~nm}$ wavelength). For EM, the labeling of ultrathin sections was performed following the same protocol but the rabbit anti-rat IgG was conjugated to colloid gold of diameter $10 \mathrm{~nm}$ (Biocell, Rancho Dominquez, CA, U.S.A.). For immunolabeling of bacterial cells, we used a rabbit antiserum directed to E. chrysanthemi 3937 LPS (Eurogentec France S.A., Angers, France) diluted 1:10,000 and then to a goat antirabbit IgG labeled with FITC diluted in PBSB-T according to the procedure outlined above.

For callose detection, the leaves were collected 8 hpi and cleared by immersion in an alcoholic lactophenol solution by the method of Shipton and Brown (1962) modified by Adam and Sommerville (1996). They were rinsed in 50\% ethanol, then in water. Callose was detected by staining for $30 \mathrm{~min}$ in a $150 \mathrm{mM} \mathrm{K} \mathrm{HPO}_{4}(\mathrm{pH} 9.5$ ) buffer containing $0.01 \%$ aniline blue (Sigma). Each leaf was mounted in $50 \%$ glycerol and observed with a Zeiss fluorescence microscope (excitation filter $365 \mathrm{~nm}$ and barrier filter $420 \mathrm{~nm}$ ).

\section{ACKNOWLEDGMENTS}

This work was supported by grants from the Institut National de Recherche Agronomique (INRA). We thank J.-P. Métraux and J. Dangl for kindly providing the seeds of sid2 and atrboh mutants, respectively, and G. Condemine for the outC mutant strain. We are particularly grateful to D. Reis for her interest in this work and critical advice in microscopy and to $\mathrm{O}$. Patrit for technical help. We also thank M.-A. Barny for helpful discussions.

\section{LITERATURE CITED}

Adam, L., and Sommerville, S. C. 1996. Genetic characterization of five powdery mildew disease resistance loci in Arabidopsis thaliana. Plant J. 9:341-356.

Alonso, J. M., Hirayama, T., Roman, G., Nourizadeh, S., and Ecker, J. R. 1999. EIN2, a bifunctional transducer of ethylene and stress responses in A. thaliana. Science. 284:2148-2152.

Bestwick, C. S., Brown, I. R., Bennett, M. H. R., and Mansfield, J. W. 1997. Localization of hydrogen peroxide accumulation during the hypersensitive reaction of lettuce cells to Pseudomonas syringae pv. phaseolicola. Plant Cell 9:209-221.

Bouley, J., Condemine, G., and Shevchik, V. E. 2001. The PDZ domain of OutC and the N-terminal region of OutD determine the secretion specificity of the type II Out pathway of E. chrysanthemi. J. Mol. Biol. 308:205-219.

Bowles, D. J. 1990. Defense-related proteins in higher plants. Annu. Rev. Biochem. 59:873-907.

Bowling, S. A., Clarke, J. D., Liu, Y., Klessig, D. F., and Dong, X. 1997. The cpr5 mutant of Arabidopsis expresses both NPR1-dependent and NPR1-independent resistance. Plant Cell. 9:1573-1584.

Broekaert, W. F., Delauré, S. L., De Bolle, M. F. C., and Cammue, B. P. A. 2006. The role of ethylene in host-pathogen interactions. Annu. Rev. Phytopath. 44:393-416.

Condemine, G., and Robert-Baudouy, J. 1995. Synthesis and secretion of Erwinia chrysanthemi virulence factors are coregulated. Mol. PlantMicrobe Interact. 8:632-636.

Dellagi, A., Rigault, M., Segond, D., Roux, C., Kraepiel, Y., Cellier, F., Briat, J.-F., Gaymard, F., and Expert, D. 2005. Siderophore-mediated upregulation of A. thaliana ferritin expression in response to Erwinia chrysanthemi infection. Plant J. 43:262-272.

De Lorenzo, G., Cervone, F., Hahn, M. G., Darvill, A., and Albersheim, P. 1991. Bacterial endopectate lyase: Evidence that plant cell wall $\mathrm{pH}$ prevents tissue maceration and increases the half-life of elicitor-active oligogalacturonides. Physiol. Mol. Plant Pathol. 39:335-344.

Douet, V., Loiseau, L., Barras F., and Py, B. 2004. Systematic analysis, by the yeast two-hybrid, of protein interaction between components of the type II secretory machinery of Erwinia chrysanthemi. Res. Microbiol. 155:71-75.

Durrant, W. E., and Dong, X. 2004. Systemic acquired resistance. Annu. Rev. Phytopathol. 42:185-209.

Expert, D. 1999. Withholding and exchanging iron: Interactions between Erwinia spp. and their plant hosts. Annu. Rev. Phytopathol. 37:307-334.

Favey, S., Labesse, G., Vouille, V., and Boccara, M. 1995. Flavohaemoglobin HmpX: A new pathogenicity determinant in Erwinia chrysanthemi strain 3937. Microbiology. 141:863-871.

Franza, T., Mahé, B., and Expert, D. 2005. Erwinia chrysanthemi requires a second iron transport route dependent of the siderophore achromobactin for extracellular growth and plant infection. Mol. Microbiol. 55:261-275.

Fujimoto, S. Y., Ohta, M., Usui, A., Shinshi, H., and Ohme-Takagi, M. 2000. A. thaliana ethylene-responsive element binding factors act as transcriptional activators or repressors of GCC box-mediated gene expression. Plant Cell. 12:393-404.

Gerber, I. B., Zeidler, D., Durner, J., and Dubery, I. A. 2004 Early perception responses of Nicotiana tabacum cells in response to lipopolysaccharides from Burkholderia cepacia. Planta. 218:647-657.

Glazebrook, J., Chen W., Estes, B., Chang, H.-R., Nawrath, C., Métraux, J.-P., Zhu, T., and Katagiri, F. 2003. Topology of the network integrating salicylate and jasmonate signal transduction derived from global expression phenotyping. Plant J. 34:217-228.

Glazebrook, J. 2005. Contrasting mechanisms of defense against biotrophic and necrotrophic pathogens. Annu. Rev. Phytopathol. 43:205-227.

Govrin, E. M., and Levine, A. 2000. The hypersensitive response facilitates plant infection by the necrotrophic pathogen Botrytis cinerea. Curr. Biol. 10:751-757.

Grant, J. J., and Loake, G. J. 2000. Role of reactive oxygen intermediates and cognate redox signaling in disease resistance. Plant Physiol 124:21-29.

Guzman, P., and Ecker, J. R. 1990. Exploiting the triple response of $A$. thaliana to identify ethylene-related mutants. Plant Cell. 2:513-523.

Hassouni, M. E., Chambost, J. P., Expert, D., Van Gijsegem, F., and Barras, F. 1999. The minimal gene set member msrA, encoding peptide methionine sulfoxide reductase, is a virulence determinant of the plant pathogen Erwinia chrysanthemi. Proc. Natl. Acad. Sci. U.S.A. 96:887-892.

He, S. Y., Schoedel, C., Chatterjee, A. K., and Collmer, A. 1991. Extracellular secretion of pectate lyase by Erwinia chrysanthemi Out pathway is dependent upon Sec-mediated export across the inner membrane. J. Bacteriol. 173:4310-4317.

Jenkins, J., Shevchik, V. E., Hugouvieux-Cotte-Pattat, N., and Pickersgill, R. W. 2004. The crystal structure of pectate lyase Pel9A from Erwinia chrysanthemi. J. Biol. Chem. 279:9139-9145.

Jha, G., Rajheshwari, R., and Sonti, R. V. 2005. Bacterial type two secretion system secreted proteins: Double-edged swords for plant-pathogens Mol. Plant-Microbe Interact. 18:891-898.

Katagiri, F. 2004. A global view of defense gene expression regulation-a highly interconnected signaling network. Curr. Opin. Plant Biol. 7:506511.

Kazemi-Pour, N., Condemine, G., and Hugouvieux-Cotte-Pattat, N. 2004. The secretome of the plant pathogenic bacterium Erwinia chrysanthemi. Proteomics. 4:3177-3186.

Kita, N., Boyd, C. M., Garett, M. R., Jurnak, F., and Keen, N. T. 1996. Differential effect of site-directed mutations in pelC on pectate lyase 
activity, plant tissue maceration, and elicitor activity. J. Biol. Chem. 271:26529-26535.

Klessig, D. F., Durner, J., Noad, R., Navarre, D. A., Wendehenne, D., Kumar, D., Zhou, J. M., Shah, J., Zhang, S., Kachroo, P., Trifa, Y., Pontier, D., Lam, E., and Silva, H. 2000. Nitric oxide and salicylic acid signaling in plant defense. Proc. Natl. Acad. Sci. U.S.A. 97:8849-8855.

Laatu, M., and Condemine, G. 2003. Rhamnogalacturonate lyase RhiE is secreted by the Out system in Erwinia chrysanthemi. J. Bacteriol. 185:1642-1649.

La Camera, S., Gouzerh, G., Dhondt, S., Hoffmann L., Fritig, B., Legrand, M., and Heitz, T. 2004. Metabolic reprogramming in plant innate immunity: The contributions of phenylpropanoid and oxylipin pathways. Immunol. Rev. 198:267-284.

Lam, E., Kato, N., and Lawton, M. 2001. Programmed cell death, mitochondria and the plant hypersensitive response. Nature 411:848-853.

Lamb, C., and Dixon, R. A. 1997. The oxidative burst in plant disease resistance. Annu. Rev. Plant Physiol. Plant Mol. 48:251-275.

Leon, J., Lawton, M. A., and Raskin, I. 1995. Hydrogen peroxide stimulates salicylic acid biosynthesis in tobacco. Plant Physiol. 108:1673-1678.

Lorenzo, O., and Solano, R. 2005. Molecular players regulating the jasmonate signalling network. Curr. Opin. Plant Biol. 8:532-540.

Meyer, A., Puhler, A., and Niehaus, K. 2001 The lipopolysaccharides of the phytopathogen Xanthomonas campestris pv. campestris induce an oxidative burst reaction in cell cultures of Nicotiana tabacum. Planta 213:214-222

Métraux, J. P. 2002. Recent breakthroughs in the study of salicylic acid biosynthesis. Trends Plant Sci. 7:332-334.

Miller, J. H. 1972. Experiments in Molecular Genetics. Cold Spring Harbor Laboratory Press, Cold Spring Harbor, NY, U.S.A.

Mou, Z., Fan, W., and Dong, X. 2003. Inducers of plant systemic acquired resistance regulate NPR1 function through redox changes. Cell 113:935944.

Murdoch, L., Corbel, J.-C., Reis, D., Bertheau, Y., and Vian, B. 1999. Differential cell wall degradation by Erwinia chrysanthemi in petiole of Saintpaulia ionantha. Protoplasma 210:59-74

Nachin, L., El Hassouni, M., Loiseau, L., Expert, D., and Barras, F. 2001. SoxR-dependent response to oxidative stress and virulence of Erwinia chrysanthemi: The key role of SufC, an orphan ABC ATPase. Mol. Microbiol. 39:960-972.

Nachin, L., Loiseau, L., Expert, D., and Barras, F. 2003. SufC: An unorthodox cytoplasmic ABC/ATPase required for [Fe-S] biogenesis under oxidative stress. EMBO (Eur. Mol. Biol. Organ.) J. 22:427-437.

Nawrath, C., and Métraux, J. P. 1999. Salicylic acid induction-deficient mutants of $A$. thaliana express PR-2 and PR-5 and accumulate high levels of camalexin after pathogen inoculation. Plant Cell.11:1393-1404.

Norman-Setterblad, C., Vidal, S., and Palva, E. T. 2000. Interacting signal pathways control defense gene expression in A. thaliana in response to cell wall-degrading enzymes from Erwinia carotovora. Mol. PlantMicrobe Interact.13:430-438

Nurnberger, T., Brunner, F., Kemmerling, B., and Piater, L. 2004. Innate immunity in plants and animals: Striking similarities and obvious differences. Immunol. Rev. 198:249-66.

Palva, T. K., Holmström, K.-O., Heino, P., and Palva, E. T. 1993. Induction of plant defense response by exoenzymes of Erwinia carotovora subsp. carotovora. Mol. Plant-Microbe Interact. 6:190-196.

Pérombelon, M. C. M. 2002. Potato diseases caused by soft rot erwinias: An overview of pathogenesis. Plant Pathol. 51:1-12.

Reymond, P., and Farmer, E. E. 1998. Jasmonate and salicylate as global signals for defense gene expression. Curr. Opin. Plant Biol. 1:404411.

Robert-Baudouy, J., Nasser, W., Condemine, G., Reverchon, S., Shevchik, V. E., and Hugouvieux-Coote-Pattat, N. 2000. Regulation of pectinase gene expression in Erwinia chrysanthemi. Pages 221-268 in: PlantMicrobe Interactions. Vol. 5. G. Stacey and N. T. Keen, eds. American Phytopathological Society Press, St. Paul, MN, U.S.A.

Roy, C., Kester, H., Visser, J., Shevchik, V. E., Hugouvieux-Cotte-Pattat, N., Robert-Baudouy, J. and Benen, J. 1999. Modes of action of five different endopectate lyases from Erwinia chrysanthemi 3937. J. Bacteriol. 181:3705-3709.

Ryan, C. A., and Farmer, E. E. 1991. Oligosaccharide signals in plants: A current assessment. Annu. Rev. Plant Physiol. Mol. Biol. 42:651-674.

Sandkvist, M. 2001. Biology of type II secretion. Mol. Microbiol. 40:271283.

Santos, R., Franza, T., Laporte, M. L., Sauvage, C., Touati, D., and Expert, D. 2001. Essential role of superoxide dismutase on the pathogenicity of Erwinia chrysanthemi strain 3937. Mol. Plant-Microbe Interact. 14:758767.

Scholl, R. L., May S. T., and Ware D. H. 2000. Seed and molecular resources for Arabidopsis. Plant Physiol. 124:1477-80.
Shah, J. 2003. The salicylic acid loop in plant defense. Curr. Opin. Plant Biol. 6:365-71.

Shevchik, V. E., Robert-Baudouy, J., and Condemine, G. 1997a. Specific interaction between OutD, an Erwinia chrysanthemi outer membrane protein of the general secretory pathway, and secreted proteins. EMBO (Eur. Mol. Biol. Organ.) J 16:3007-3016.

Shevchik, V. E., Robert-Baudouy, J., Hugouvieux-Cotte-Pattat, N. 1997b. The pectate lyase PelI of Erwinia chrysanthemi belongs to a new family. J. Bacteriol. 179:7321-7330.

Shipton, W. A., and Brown, J. F. 1962. A whole-leaf clearing and staining technique to demonstrate host-pathogen relationships of wheat stem rust. Phytopathology. 52:1313.

Shirasu, K., Nakajima, H., Rajasekhar, V. K., Dixon, R. A., and Lamb, C. 1997. Salicylic acid potentiates an agonist-dependent gain control that amplifies pathogen signals in the activation of defense mechanisms. Plant Cell. 9:261-270.

Simons, B. H., Millenaar, F. F., Mulder, L., Van Loon, L. C., and Lambers, H. 1999. Enhanced expression and activation of the alternative oxidase during infection of A. thaliana with Pseudomonas syringae pv. tomato. Plant Physiol. 120:529-538.

Smallwood, M., Martin, H., and Knox, J. P. 1995. An epitope of rice threonine- and hydroxyprolinerich glycoprotein is common to cell wall and hydrophobic plasma-membrane glycoproteins. Planta 196:510-522.

Staswick, P. E., Su, W., and Howell, S. H. 1992. Methyl jasmonate inhibition of root growth and induction of a leaf protein are decreased in an A. thaliana mutant. Proc. Natl. Acad. Sci. U.S.A. 89:6837-6840.

Staswick, P. E., Tiryaki, I., and Rowe, M. L. 2002. Jasmonate response locus JAR1 and several related $A$. thaliana genes encode enzymes of the firefly luciferase superfamily that show activity on jasmonic, salicylic, and indole-3-acetic acids in an assay for adenylation. Plant Cell 14:1405-1415.

Sticher, L., Mauch-Mani, B., and Métraux, J.-P. 1997. Systemic acquired resistance. Annu. Rev. Phytopathol. 35:235-70.

Summermatter, K., Sticher, L., and Métraux, J. P. 1995. Systemic responses in Arabidopsis thaliana infected and challenged with Pseudomonas syringae pv. syringae. Plant Physiol. 108:1379-1385.

Thomma, B. P., Eggermont, K., Tierens, K. F., and Broekaert, W. F. 1999. Requirement of functional ethylene-insensitive 2 gene for efficient resistance of $A$. thaliana to infection by Botrytis cinerea. Plant Physiol. 121:1093-1102.

Torres, M. A., Dangl, J. L., and Jones, J. D. 2002. A. thaliana gp91phox homologues AtrbohD and AtrbohF are required for accumulation of reactive oxygen intermediates in the plant defense response. Proc. Natl. Acad. Sci. U.S.A. 99:517-522.

Torres, M. A., Jones, J. D., and Dangl, J. L. 2005. Pathogen-induced, NADPH oxidase-derived reactive oxygen intermediates suppress spread of cell death in A. thaliana. Nat. Genet. 37:1130-1134.

Torres, M. A., Jones, J. D., and Dangl, J. L. 2006. Reactive oxygen species signaling in response to pathogens. Plant Physiol. 141:373-378.

Truman, W., de Zabala, M. T., and Grant, M. 2006. Type III effectors orchestrate a complex interplay between transcriptional networks to modify basal defence responses during pathogenesis and resistance. Plant J. 46:14-33.

Van Loon, L. C., Geraats, B. P., and Linthorst, H. J. 2006. Ethylene as a modulator of disease resistance in plants. Trends Plant Sci. 11:184-191.

Vasquez-Torres, A., Xu, Y., Jones-Carson, J., Holden, D., Lucia, S. M. Dinauer, M. C., Mastroeni, P., and Fang, F. C. 2000. Salmonella pathogenicity island 2-dependent evasion of the phagocyte NADPH oxidase. Science 287:1655-1658.

Venisse, J. S., Gullner, G., and Brisset, M. N. 2001 Evidence for the involvement of an oxidative stress in the initiation of infection of pear by Erwinia amylovora. Plant Physiol. 125:2164-2172.

Verwoerd, T. C., Dekker, B. M., and Hoekema, A. 1989. A small-scale procedure for the rapid isolation of plant RNAs. Nucleic Acids Res. 17:2362.

Wildermuth, M. C., Dewdney, J., Wu, G., and Ausubel, F. 2001. Isochorismate synthase is required to synthetize salicylic acid for plant defence. Nature 414:562-565

Willats, W. G. T., McCartney, L., Mackie, W., and Knox, J. P. 2001. Pectin: Cell biology and prospects for functional analysis. Plant Mol. Biol. 47:927.

Xu, L., Liu, F., Lechner, E., Genschik, P., Crosby, W. L., Ma, H., Peng, W., Huang, D., and Xie, D. 2002. The SCF(COI1) ubiquitin-ligase complexes are required for jasmonate response in Arabidopsis. Plant Cell 14:1919-35.

\section{AUTHOR-RECOMMENDED INTERNET RESOURCE}

CAZY (Carbohydrate-Active enZymes) website: afmb.cnrs-mrs.fr/CAZY/ 